\title{
Synthesis And Physico-Chemical Investigations On Some Bis(Carbodithioato)Nitrosyl Complexes Of Cobalt(I)
}

\author{
${ }^{a}$ Shashi B. Kalia*, ${ }^{a}$ Mridula, ${ }^{\mathrm{a}}$ Rajesh Kumar and ${ }^{\mathrm{b}}$ Anil Thakur \\ ${ }^{a}$ Department of Chemistry, Himachal Pradesh University Shimla-171005 India \\ ${ }^{b}$ Department of Biotechnology, Shoolini University, Solan (H.P.), India
}

\begin{abstract}
Some bis(carbodithioato)nitrosyl complexes of cobalt(I) of the general formula $\left[\mathrm{Co}(\mathrm{NO})(\mathrm{L})_{2}\right](\mathrm{L}=4$ MPipzcdt, 4-EtPipzcdt, Morphcdt and Pipdcdt) have been prepared and characterized by elemental analysis, molar conductance, mass, infrared, NMR $\left({ }^{1} \mathrm{H},{ }^{13} \mathrm{C}\right.$ and $\left.{ }^{15} \mathrm{~N}\right)$ and solution electronic absorption spectra and room temperature field dependent magnetic susceptibility measurements. The complexes are diamagnetic corresponding to cobalt(I), a d system. The ligand 4-MPipzcdtNa. $\mathrm{H}_{2} \mathrm{O}$ and its cobalt(I) nitrosyl complex have also been screened against some pathogenic bacteria, viz. Escherichia coli, Salmonella typhi, Enterobacter, Psuedomonas aeruginosa, Shigella flexneri, S.Epidermidis and Salmonella typhimurium, for assaying their antimicrobial activity.
\end{abstract}

Keywords: Heterocyclic carbodithioate, Cobalt(I), Nitric oxide, Magnetic, Spectra.

\section{Introduction}

A large number of transition metal complexes with various aliphatic, aromatic and heterocyclic dithiocarbamate ligands have been reported ${ }^{1}$. Dithiocarbamates are an important class of ligands, being capable of stabilising transition metals in a wide range of oxidation states. In by far the vast majority of instances, they act merely as non-sterically demanding ancillary ligands. ${ }^{2,3}$ It is however, becoming increasingly clear that under certain circumstances the ligand can behave in a non-innocent fashion ${ }^{3}$ (addition of dithiocarbamates to unsaturated ligands and insertion of unsaturated groups into metal-sulphur bond(s) of dithiocarbamates). ${ }^{2}$ The major advantage of using the small bite-angle of dithiocarbamato moiety as a stabilising chelating ligand, is its unique property to remain intact under a variety of reaction conditions. ${ }^{4,5}$ The ability of the dithiocarbamate ligands (innocent ligand) to stabilize cobalt in its low oxidation state in conjugation with $\pi$-acid ligand, i.e. nitrosyl (non-innocent ligand) has been explored in the present study with heterocyclic carbodithioate ligands. Intense interest in the chemistry and biochemistry of $\mathrm{NO}$ and their derivatives such as metal nitrosyl complexes is because of the strategies of these complexes to deliver NO to biological targets on demand. ${ }^{6,7}$ The role of biomimicry in metal nitrosyl complex systems is based on the fact they undergo one electron oxidation and reduction processes. ${ }^{8} \mathrm{NO}$, 'Molecule' of the Year, 1992, had also been proclaimed as a fundamental player in the fields of mammalian bioregulation, immunology and neuroscience. This has further stimulated intense interest in the chemistry and biochemistry of derivatives of metal nitrosyl complexes. ${ }^{9}$ Such type of derivatives have been studied much in detail for iron metal ion while the electronic description of cobalt complexes has not been probed as effectively as those of their iron analogues.

\section{Material and Methods}

\section{Experimental}

All the chemicals used were of analytical reagent grade and used as such.

\section{Preparation Of Ligands:}

Sodium4-methylpiperazine-1-carbodithioatemonohydrate(4-MPipzcdtNa. $\mathrm{H}_{2} \mathrm{O}$ ), sodium 4-ethylpiperazine1-carbodithioatemonohydrate (4-EtPipzcdtNa. $\mathrm{H}_{2} \mathrm{O}$ ) and sodium morpholine carbodithioate monohydrate (MorphedtNa.H $\mathrm{H}_{2} \mathrm{O}$ ):

Heterocyclic secondary amine (1-methylpiperazine: $1.15 \mathrm{~g} ; 11.5 \mathrm{mmol}$, 1-ethylpiperazine: $1.31 \mathrm{~g} ; 11.5$ mmol and morpholine: $1.0 \mathrm{~g} ; 11.5 \mathrm{mmol})$ in ethanol $(15 \mathrm{ml})$ was cooled to $5^{\circ} \mathrm{C}$. To this cooled solution, carbon disulphide $(0.87 \mathrm{~g} ; 11.5 \mathrm{mmol}$ ) was slowly added with stirring. A cream coloured (in case of 1-MPipz and 1EtPipz) and white coloured (in case of morpholine) solid carbodithioic acid separated immediately. It was filtered, washed with ethanol and diethyl ether and air dried. To the solid carbodithioic acid, viz. 4methylpiperazine-1-carbodithioic acid (4-MPipzcdtH), 4-ethylpiperazine-1-carbodithioic acid (4-EtPipzcdtH) and morpholinecarbodithioic acid (MorphcdtH) $(1.08 \mathrm{~g} ; 6.13 \mathrm{mmol}, 1.16 \mathrm{~g} ; 6.13 \mathrm{mmol}$ and $1.0 \mathrm{~g} ; 6.13 \mathrm{mmol}$ respectively) was added sodium hydroxide $(0.24 \mathrm{~g} ; 6.13 \mathrm{mmol})$ dissolved in minimum quantity of water $(2 \mathrm{ml})$. This resulting solution was filtered and the filtrate was evaporated to dryness on water bath. The solid sodium 
carbodithioate thus obtained was stored in a calcium chloride desiccator. 4-MPipzcdtNa. $\mathrm{H}_{2} \mathrm{O}$, Yield: $92 \%$, Decomposition temp. $268{ }^{\circ} \mathrm{C}$, Anal. Calcd. for $\mathrm{C}_{6} \mathrm{H}_{13} \mathrm{~N}_{2} \mathrm{~S}_{2} \mathrm{ONa}(\%)$ : C, 33.33; H, 6.02; N, 12.96; S, 29.43. Found: C, 33.66; H, 6.51; N, 12.52; S, 29.56. 4-EtPipzcdtNa. $\mathrm{H}_{2} \mathrm{O}$, Yield: $93 \%$, Decomposition temp. $242{ }^{0} \mathrm{C}$, Anal. Calcd. for $\mathrm{C}_{7} \mathrm{H}_{15} \mathrm{~N}_{2} \mathrm{~S}_{2} \mathrm{ONa}(\%)$ : C, 36.52; H, 6.65; N, 12.17; S, 27.83. Found: C, 36.74; H, 6.52; N, 12.21; S, 27.54. MorphcdtNa. $\mathrm{H}_{2} \mathrm{O}$, Yield: $90 \%$, Decomposition temp. $290{ }^{\circ} \mathrm{C}$, Anal. Calcd. for $\mathrm{C}_{5} \mathrm{H}_{10} \mathrm{O}_{2} \mathrm{NS}_{2} \mathrm{Na}(\%)$ : C, 29.55; H, 4.92; N, 6.89; S, 31.52. Found: C, 29.10; H, 4.98; N, 6.53; S, 31.10.

Sodium piperidine carbodithioate dihydrate (PipdcdtNa.2 $\left.\mathrm{H}_{2} \mathrm{O}\right)$ :

Piperidine $(0.977 \mathrm{~g} ; 11.5 \mathrm{mmol})$ in ethanol $(15 \mathrm{ml})$ was cooled to $5^{0} \mathrm{C}$. To this cooled solution carbon disulphide $(0.87 \mathrm{~g} ; 11.5 \mathrm{mmol})$ was added slowly with stirring when white solid separated. To this solid was added sodium hydroxide $(0.46 \mathrm{~g} ; 11.5 \mathrm{mmol})$ dissolved in minimum quantity of water $(4 \mathrm{ml})$. The resulting solution was filtered and the filtrate was evaporated to dryness on water bath. The product was stored in a calcium chloride desiccator. PipdcdtNa. $2 \mathrm{H}_{2} \mathrm{O}$, Yield: $90 \%$, Decomposition temp. $214{ }^{0} \mathrm{C}$, Anal. Calcd. for $\mathrm{C}_{6} \mathrm{H}_{14} \mathrm{O}_{2} \mathrm{NS}_{2} \mathrm{Na}(\%): \mathrm{C}, 32.88 ; \mathrm{H}, 6.39 ; \mathrm{N}, 6.39 ; \mathrm{S}, 29.22$. Found: C, $32.93 ; \mathrm{H}, 6.55 ; \mathrm{N}, 5.99 ; \mathrm{S}, 29.87$.

\section{Preparation of the complexes:}

[Co(NO) $\left.(\mathrm{L})_{2}\right](\mathrm{L}=$ 4-MPipzcdt, 4-EtPipzcdt, Morphedt and Pipdcdt):

A solution of $\mathrm{Co}\left(\mathrm{ClO}_{4}\right)_{2} \cdot 6 \mathrm{H}_{2} \mathrm{O}(0.040 \mathrm{~g} ; 1.09 \mathrm{mmol})$ in $120 \mu \mathrm{l}$ of carefully degassed ethanol was cooled to $0^{0} \mathrm{C}$ in an ice bath and saturated with purified nitric oxide gas*. A cooled solution of $(0.0472 \mathrm{~g} ; 0.218 \mathrm{mmol}$ for 4-MPipzcdtNa. $\mathrm{H}_{2} \mathrm{O}, 0.0502 \mathrm{~g} ; 0.218 \mathrm{mmol}$ for 4-EtPipzcdtNa. $\mathrm{H}_{2} \mathrm{O}, 0.0442 \mathrm{~g} ; 0.218 \mathrm{mmol}$ for MorphcdtNa. $\mathrm{H}_{2} \mathrm{O}$ and $0.0478 \mathrm{~g} ; 0.218 \mathrm{mmol}$ for PipdcdtNa. $\mathrm{H}_{2} \mathrm{O}$ ) in $80 \mu \mathrm{l}$ of degassed ethanol was added to it immediately in a single lot and the mixture was stirred for 20 minutes while keeping it in the ice bath. The excess nitric oxide was removed from the system by passing nitrogen gas through the solution until no further brown fumes were observed, this stage was reached in about 2-4 minutes. The brown precipitates were obtained. Centrifugation was done to avoid losses of the complex. It was washed several times with degassed ethanol using centrifugation technique and dried in $\mathrm{CaCl}_{2}$ desiccator. [Co(NO)(4-MPipzcdt) $)_{2}$, Yield: $60 \%$, Decomposition temp. $240{ }^{\circ} \mathrm{C}$, Anal. Calcd. for $\mathrm{CoC}_{12} \mathrm{H}_{22} \mathrm{~N}_{5} \mathrm{~S}_{4} \mathrm{O}(\%)$ : C, 32.80; H, 5.01; N, 15.94; S, 29.15; Co, 13.43. Found: C, 32.91; H, 5.15; N, 15.91; S, 28.98; Co, 13.39. [Co(NO)(4-EtPipzcdt) $)_{2}$, Yield: $62 \%$, Decomposition temp. $227^{\circ} \mathrm{C}$, Anal. Calcd. for $\mathrm{CoC}_{14} \mathrm{H}_{26} \mathrm{~N}_{5} \mathrm{~S}_{4} \mathrm{O}(\%)$ : C, 35.97; H, 5.56; N, 14.98; S, 27.40; Co, 12.63. Found: $\mathrm{C}, 36.10 ; \mathrm{H}, 5.48 ; \mathrm{N}, 14.89 ; \mathrm{S}, 27.55 ; \mathrm{Co}, 12.31$. [Co(NO)(Morphcdt) $)_{2}$, Yield: $61 \%$, Decomposition temp. $262{ }^{\circ} \mathrm{C}$, Anal. Calcd. for $\mathrm{CoC}_{10} \mathrm{H}_{16} \mathrm{~N}_{3} \mathrm{~S}_{4} \mathrm{O}_{3}(\%): \mathrm{C}, 29.05 ; \mathrm{H}, 3.87 ; \mathrm{N}, 10.16 ; \mathrm{S}, 30.99$; Co, 14.28. Found: C, 29.56; H, 3.81; N, 10.09; S, 30.74; Co, 14.31. [Co(NO)(Pipdedt) $)_{2}$, Yield: $62 \%$, Decomposition temp. $190{ }^{\circ} \mathrm{C}$, Anal. Calcd. for $\mathrm{CoC}_{12} \mathrm{H}_{20} \mathrm{~N}_{3} \mathrm{~S}_{4} \mathrm{O}(\%)$ : C, 35.20; H, 4.88; N, 10.26; S, 31.29; Co, 14.42. Found: C, 34.97; H, 4.82; N, 10.21; S, 31.27; Co, 14.38.

*Sulphuric acid (50\%) was added dropwise to a solution of $10 \mathrm{~g}$ of $\mathrm{KNO}_{2}$ and $5 \mathrm{~g}$ of $\mathrm{KI}$ in $35 \mathrm{ml} \mathrm{of} \mathrm{H}_{2} \mathrm{O}$. The gas was washed with $90 \%$ sulphuric acid and purified by passing it through three traps of $50 \% \mathrm{KOH}$ solution.

$* 2 \mathrm{KNO}_{2}+\mathrm{KI}+\mathrm{H}_{2} \mathrm{SO}_{4} \rightarrow \mathrm{K}_{2} \mathrm{SO}_{4}+2 \mathrm{NO} \uparrow+\mathrm{I}_{2}$

\section{Elemental analyses}

Carbon and hydrogen analyses were performed on an automatic Coleman-33 Analyser while nitrogen was analysed by Kjeldahl's method. The cobalt metal was determined volumetrically by EDTA method using murexide indicator while sulphur was determined gravimetrically as barium sulphate.

\section{Physical measurements}

NMR spectra of the ligands 4-RPipzcdtNa. $\mathrm{H}_{2} \mathrm{O}(\mathrm{R}=\mathrm{M}, \mathrm{Et})$ and their complexes and ${ }^{13} \mathrm{C}$ and ${ }^{15} \mathrm{~N}$ spectra for [Co(NO)(4-MPipzcdt $)_{2}$ ] were recorded on av500 $\mathrm{MHz}$ spectrophotometer using $\left(\mathrm{CD}_{3}\right)_{2} \mathrm{SO}$ as solvent and TMS as an internal standard. Infrared spectra of all the ligands and complexes were recorded as $\mathrm{KBr}$ pellets on Nicolet 5700 FT Infrared Spectrophotometer in the $4000-600 \mathrm{~cm}^{-1}$ region. Infrared spectra of all the complexes were recorded as nujol mull with cesium chloride plates as windows in the $600-200 \mathrm{~cm}^{-1}$ region. The mass spectra of DMSO:ACN $(2 \mathrm{mg} / 10 \mathrm{ml})$ solution of the complex, i.e. [Co(NO)(4-MPipzcdt) $)_{2}$ ] was recorded on an Agilent LCMS (6300) Ion-Trap mass spectrometer by Electron spray ionization (ESI) source having temperature of $300{ }^{0} \mathrm{C}$ using EMD ion detector. Molar conductance measurements $\left(10^{-3} \mathrm{M}\right.$ DMSO solutions) were made at $25 \pm 1{ }^{\circ} \mathrm{C}$ using Elico Conductivity Bridge type CM-82T. Solution (ethanol) electronic absorption spectra of the complexes with solvent as the reference, in quartz glass cells were recorded on Cary 100 Bio UV-Visible recording Spectrophotometer (range 900-200 nm) and Shimadzu UV-Visible 1700 recording spectrophotometer (range 1100-200 nm). Field dependent magnetic susceptibilities of the complexes were also measured on a Vibrating Sample Magnetometer PAR-155 (model-152). 


\section{In Vitro Antimicrobial Activity Screening:}

As a preliminary screening for antimicrobial activity, compounds were tested against pathogenic bacterial strains: Escherichia coli, Salmonella typhi, Enterobacter, S.Epidermidis, Psuedomonas aeruginosa, Shigella flexneri and Salmonella typhimurium. Stock solutions (1000 $\mu \mathrm{g} / \mathrm{ml})$ of the ligand, (4-MPipzcdtNa. $\left.\mathrm{H}_{2} \mathrm{O}\right)$ and its metal complex were prepared in DMSO. Quantitative antibacterial activities of the compounds were determined using 2-fold serial dilution method. MIC was considered minimum inhibitory concentration of test compound that inhibited visible growth of bacteria after $24 \mathrm{~h}$ incubation at $37^{\circ} \mathrm{C}$. Uniform volume $(125 \mu \mathrm{L})$ of nutrient broth was dispensed in all the wells of 8 rows of 96 Well Cell Culture Plate. Pure DMSO $(125 \mu \mathrm{L})$ as blank solvent was taken in the first column of the culture plate. Afterwards $125 \mu \mathrm{L}(1000 \mu \mathrm{g} / \mathrm{ml}$ conc.) of the solution of the test sample was added to the second well of all the seven rows of the culture plate except the eighth row (resultant concentration of test sample $=500 \mu \mathrm{g} / \mathrm{mL}$ ). Serial dilution method was applied to the remaining wells of all the seven rows, so as to achieve the serial concentrations, viz. $250 \mu \mathrm{g} / \mathrm{mL}, 125 \mu \mathrm{g} / \mathrm{mL}$, $62.5 \mu \mathrm{g} / \mathrm{mL}, 31.25 \mu \mathrm{g} / \mathrm{mL}, 15.62 \mu \mathrm{g} / \mathrm{mL}, 7.81 \mu \mathrm{g} / \mathrm{mL}, 3.90 \mu \mathrm{g} / \mathrm{mL}, 1.95 \mu \mathrm{g} / \mathrm{mL}, 0.975 \mu \mathrm{g} / \mathrm{mL}$ and $0.486 \mu \mathrm{g} / \mathrm{mL}$ in each row. Uniform volume of innoculum $(10 \mu \mathrm{L})$ of particular test organism was added to each row except for the control (blank) which receives only the nutrient broth and DMSO. The eighth row of the culture plate was used for the reference drug, i.e. Penicillin. The inoculated culture plates covered with lids were incubated at $37^{\circ} \mathrm{C}$ for $20-24 \mathrm{hr}$ in shaker at $162 \mathrm{rpm}$. The growth was compared with that of control culture by measuring the absorbance at $620 \mathrm{~nm}$ after 20-24 hr on Shimadzu-1700 UV-Vis spectrophotometer. The results were compared with that of Penicillin, a standard broad-spectrum antibiotic for bacterial strains. Blank tests have shown that DMSO in the preparation of the test solution does not affect the results.

\section{Results and Discussion} (Equation.1).

Sodium carbodithioate ligands of heterocyclic secondary amines were obtained according to the

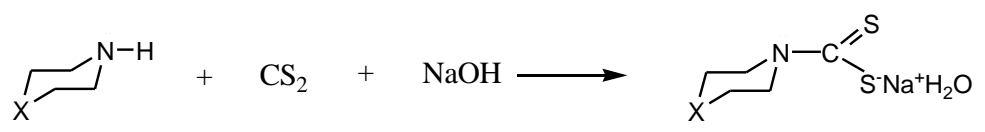

1-MPipz : $\mathrm{X}=\mathrm{N}-\mathrm{CH}_{3}$

1-EtPipz : $\mathrm{X}=\mathrm{N}-\mathrm{CH}_{2} \mathrm{CH}_{3}$

Morph : $\mathrm{X}=\mathrm{O}$

Pipd : $\mathrm{X}=\mathrm{CH}_{2}$

Nitrosyl complexes with empirical formula $\left[\mathrm{Co}(\mathrm{NO})(\mathrm{L})_{2}\right]$ (L=4-MPipzcdt, 4-EtPipzcdt, Morphcdt and Pipdedt) deduced from elemental analysis data were synthesized following the reactions ${ }^{10}$ (Equation 2.1, 2.2).

$\mathrm{Co}\left(\mathrm{ClO}_{4}\right)_{2} \cdot 6 \mathrm{H}_{2} \mathrm{O} \longrightarrow \mathrm{NO}$
$\left[\mathrm{Co}(\mathrm{NO})(\mathrm{EtOH})_{5}\right]\left(\mathrm{ClO}_{4}\right)_{2}+2 \mathrm{NaL} \longrightarrow\left[\mathrm{Co}(\mathrm{NO})(\mathrm{EtOH})_{5}\right]\left(\mathrm{ClO}_{4}\right)_{2}$$\left[\begin{array}{l}\longrightarrow \\ \longrightarrow\end{array}\right.$

(L= 4-MPipzcdt, 4-EtPipzcdt, Morphcdt, Pipdcdt)

All the complexes do not melt but decompose between $\left(190-290{ }^{\circ} \mathrm{C}\right)$.The complexes are sparingly soluble in ethanol, have some solubility in methanol and are fairly soluble in DMSO.

\section{Molar Conductance Studies:}

The $10^{-3}$ M DMSO solution of complexes exhibits molar conductance values between $\left(15-24 \mathrm{ohm}^{-1} \mathrm{~cm}^{2}\right.$ $\mathrm{mol}^{-1}$ ) (Table-1) which reveal non-electrolytic and, therefore, non-conducting nature of all the complexes.

\section{Mass Spectra:}

An interesting fragmentation pattern for the complex, as illustrated in Scheme-1 reveals the presence of molecular ion peak due to $\left[\mathrm{Co}(\mathrm{NO})(4-\mathrm{MPipzcdt})_{2}\right]^{+}$of $\mathrm{m} / \mathrm{z}=438.9(53.1 \%) .{ }^{59} \mathrm{Co}$ isotope has $100 \%$ natural abundance.

(Figure1) shows the mass fragmentation pattern of ions. The ionization resulting into monocation radical formation leaves positive charge on the nitrogen atom. This is followed by Co-NO bond cleavage wherein nitrogen of NO takes away alongwith its lone pair of electrons as well as radical electron from the nitrogen of the ring (Step-II) and cation (II) is formed. This is in consonance with the fact that nitrosyl ligand is formally regarded sometimes as $\mathrm{NO}^{+}$, sometimes as $\mathrm{NO}^{-}$, but is usually eliminated as stable neutral oxide, $\mathrm{NO}$ (ligands with formal charge can be eliminated as stable neutral molecule comparatively easily). ${ }^{11}$ The cation (II) fragmentation starts with cleavage of the $\alpha$-bond, shift of the electron density and formation of a double bond between this nitrogen atom and the carbon atom of the dithiocarbamate group, such that obtained cation (III) and the cation (II) have the same relations of $\mathrm{m} / \mathrm{z}=409$ (19.14 \%) but with different structures. The cation (IV), $\mathrm{m} / \mathrm{z}=351(15.95 \%)$ for complex, is a result of intermolecular rearrangement prior to fragmentation, involving migration of the $\alpha$-hydrogen atom across the six member heterocyclic ring of 4-MPipzcdt ligand, followed by 
simultaneous cleavage of 4-5 bond. Then cation (IV) get generated consequence upon loss of the $\mathrm{CH}_{3} \mathrm{CH}_{2} \mathrm{NCH}_{3}$ fragment. Next step involves the movement of the $\beta$-hydrogen atom, alongwith the bond electron pair to the nitrogen atom of cation (IV), followed by cleavage of the 1-6 bond. This is facilitated by stabilization of the resulting highly pronounced peak at $\mathrm{m} / \mathrm{z}=325(100 \%)$. This intensive ion $(\mathrm{V})$ represents the base peak of the complex. Formation of cation (V), occurs upon elimination of ethyne. In the next step ion (VI) corresponding to peak at $\mathrm{m} / \mathrm{z}=310(1.06 \%)$ corresponds to the fragmentation of ammonia and formation of cation (VI). The mass ion peak at $\mathrm{m} / \mathrm{z}=310$ indicates the elimination of one of the heterocyclic rings of 4-MPipzcdt ligand. Afterwards exactly same fragmentation behaviour has been observed for the second heterocyclic ring of 4-MPipzcdt ligand from the cation (II) (Step-III), exhibiting intermediate ions at $\mathrm{m} / \mathrm{z}=252(72.3 \%), \mathrm{m} / \mathrm{z}=226(19.14 \%)$ and $\mathrm{m} / \mathrm{z}=211(2.12 \%)$, with the formation of cation, i.e. $\left[\mathrm{Co}\left(\mathrm{CS}_{2}\right)_{2}\right]^{4+}, \mathrm{m} / \mathrm{z}=211$ as the apparent final product. ${ }^{12}$

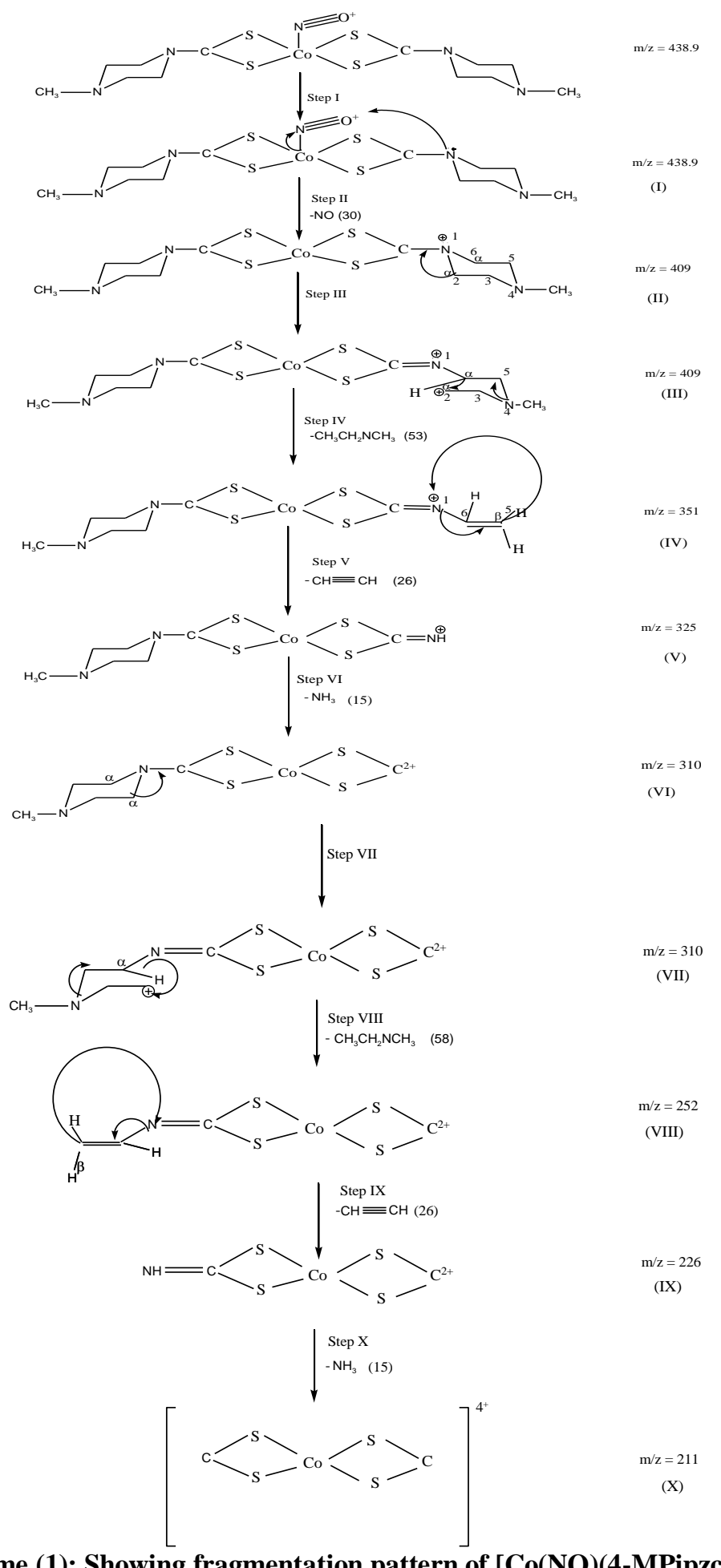

Scheme (1): Showing fragmentation pattern of [Co(NO)(4-MPipzcdt $\left.)_{2}\right]$ 


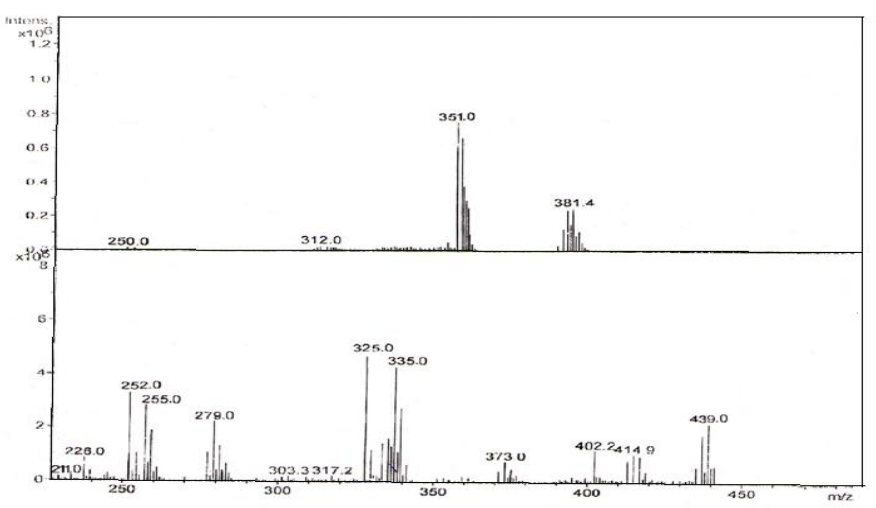

Figure 1 : Mass spectrum of $\left[\mathrm{Co}(\mathrm{NO})(4-\mathrm{MPipzcdt})_{2}\right]$

\section{Infrared Spectral Studies:}

In all the cobalt nitrosyl carbodithioates the $v(\mathrm{C}=-\mathrm{N})$ band has been observed at higher energies around (1489-1500 $\left.\mathrm{cm}^{-1}\right)$ in comparison to free ligands $\left(1450-1467 \mathrm{~cm}^{-1}\right)$ (Table-1). The rise in C-N stretching frequency has been attributed to a considerable double bond character of the $\mathrm{C}=-\mathrm{N}$ bond in the complexes. ${ }^{13}$ Observation of two bands in the region $960-1015 \mathrm{~cm}^{-1}$ (separated by less than $20 \mathrm{~cm}^{-1}$ ) for the antisymmetric $v_{\mathrm{a}}$ (SCS) vibration and one band for the symmetric $v_{\mathrm{S}}$ (SCS) stretch in the region $663-686 \mathrm{~cm}^{-1}$ (Table-1) in the IR spectra of complexes, suggest the unsymmetrical chelating bidentate mode of coordination to the metal ion. ${ }^{14}$ In the far-IR spectra of the complexes, additional bands in the $366-360 \mathrm{~cm}^{-1}$ region as compared to the free ligands, ascribable to the $v(\mathrm{Co}-\mathrm{S})$ stretching mode have been observed. ${ }^{15,16}$ In addition all the complexes exhibit three peaks in the region 291-315 $\mathrm{cm}^{-1}$, because of (Co-NO) absorptions possibly reflecting the threefold Co-N-O disorder corresponding to bent Co-NO binding mode $^{17}$ (in contrast for the M-NO stretching region, the complexes exhibit a single sharp peak for the ordered linear M-NO group). For the free intermediate, i.e. $\left[\mathrm{Co}(\mathrm{NO})(\mathrm{EtOH})_{5}\right]\left(\mathrm{ClO}_{4}\right)_{2}$ (Equation 2.2) (obtained by passing $\mathrm{NO}$ through degassed ethanolic solution of $\left.\mathrm{Co}\left(\mathrm{ClO}_{4}\right)_{2} \cdot 6 \mathrm{H}_{2} \mathrm{O}\right)$, the $v_{\mathrm{NO}}$ appears at $1687 \mathrm{~cm}^{-1}$ as a strong band, while this band has shifted to lower energy in the complexes $\left[\mathrm{Co}(\mathrm{NO})(\mathrm{cdt})_{2}\right]$ because of the increased electron density due to the carbodithioate ligand, which results into the increased back bonding from metal to the $\mathrm{NO}^{+}$and weakening of the $\mathrm{N} \equiv \mathrm{O}$ bond. The band in the complexes, lie in the range $1657-1639 \mathrm{~cm}^{-1}$ which is the range for the bent NO ligand. Such an observation has earlier been made for $\left[\mathrm{Co}(\mathrm{NO})\left(\mathrm{S}_{2} \mathrm{CNMe}_{2}\right)_{2}\right]$ being elucidated using X-ray crystallography study. ${ }^{8,}{ }^{17}, 18 \mathrm{The}$ complex also exhibits $v_{\mathrm{NO}}$ at $1630 \mathrm{~cm}^{-1}$, for its bent Co-NO linkage.

Table 1: Some coordinatively diagnostic features of infrared spectra $\left(\mathrm{cm}^{-1}\right)$ and molar conductance values, ${ }_{\mathrm{m}}\left(\mathrm{ohm}^{-1} \mathrm{~cm}^{2} \mathrm{~mol}^{-1}\right)$ of various carbodithioate ligands and their cobalt nitrosyl complexes.

\begin{tabular}{|c|c|c|c|c|c|c|c|c|c|c|}
\hline $\begin{array}{l}\text { Sr. } \\
\text { No. }\end{array}$ & Compound & $\mathrm{v}(\mathrm{N}-\mathrm{H}) /(\mathrm{O}-\mathrm{H})$ & $\begin{array}{c}\mathrm{v}(\mathrm{C}-\mathrm{H}) \\
\left(\mathrm{H}_{3} \mathrm{C}-\mathrm{N} \text { or } \mathrm{H}_{5} \mathrm{C}_{2}-\mathrm{N}\right)\end{array}$ & $v(C=-N)$ & $\mathrm{v}_{\mathrm{a}}(\mathrm{SCS})$ & $v_{s}(\mathrm{SCS})$ & $\mathrm{v}(\mathrm{N} \equiv 0)$ & $v(\mathrm{C} 0-\mathrm{S})$ & $\mathrm{v}\left(\mathrm{C}_{0}-\mathrm{N}\right)$ & $\wedge \mathrm{m}$ \\
\hline 1. & 4-MPipzcdtNa. $\mathrm{H}_{2} \mathrm{O}$ & $3460-3160 \mathrm{~b}, \mathrm{~s}$ & $2808 \mathrm{~s}$ & $1455 \mathrm{~s}$ & $989 \mathrm{~s}, 971 \mathrm{~m}$ & $686 w$ & - & - & - & - \\
\hline 2. & 4-EtPipzcdtNa. $\mathrm{H}_{2} \mathrm{O}$ & $3465-3160 \mathrm{~b}, \mathrm{~s}$ & $2818 \mathrm{~s}$ & $1460 \mathrm{~s}$ & $997 \mathrm{~s}, 1015 \mathrm{~m}$ & $680 w$ & - & - & - & - \\
\hline 3. & MorphcdtNa. $\mathrm{H}_{2} \mathrm{O}$ & $3415-3310 \mathrm{~b}, \mathrm{~s}$ & - & $1450 \mathrm{~s}$ & $980 \mathrm{~s}, 996 \mathrm{~m}$ & $678 w$ & - & - & - & - \\
\hline 4. & PipdddtNa. $2 \mathrm{H}_{2} \mathrm{O}$ & $3400-3160 \mathrm{~b}, \mathrm{~s}$ & - & $1467 \mathrm{~s}$ & $964 \mathrm{~s}, 982 \mathrm{~m}$ & $670 w$ & - & - & - & - \\
\hline 5. & {$\left[\mathrm{Co}(\mathrm{NO})(4-\mathrm{MPipzcdt})_{2}\right]$} & - & $2859 \mathrm{~s}$ & $1491 \mathrm{~s}$ & $985 \mathrm{~s}, 968 \mathrm{~m}$ & $679 w$ & 1649 & 365 & $\begin{array}{c}296,302, \\
313\end{array}$ & 20 \\
\hline 6. & {$[\mathrm{Co}(\mathrm{NO})(4-\mathrm{EtPipzcdt})]$} & - & $2865 \mathrm{~s}$ & $1495 \mathrm{~s}$ & $995 \mathrm{~s}, 1012 \mathrm{~m}$ & $672 w$ & 1639 & 366 & $\begin{array}{l}298,305 \\
315\end{array}$ & 19 \\
\hline 7. & {$\left[\mathrm{Co}(\mathrm{NO})(\text { Morphcdt })_{2}\right]$} & - & - & $1489 \mathrm{~s}$ & $973 \mathrm{~s}, 991 \mathrm{~m}$ & $671 w$ & 1655 & 363 & $\begin{array}{l}295,300 \\
310\end{array}$ & 24 \\
\hline 8. & {$\left[\mathrm{Co}(\mathrm{NO}) /\left(\mathrm{Pipdcdt}_{2}\right]\right.$} & - & - & $1500 \mathrm{~s}$ & $960 \mathrm{~s}, 977 \mathrm{~m}$ & $663 w$ & 1657 & 360 & $\begin{array}{l}291,295 \\
307\end{array}$ & 15 \\
\hline
\end{tabular}




\section{Proton NMR Spectra:}

The free ligands, viz. 4-MPipzcdtNa. $\mathrm{H}_{2} \mathrm{O}$ and 4-EtPipzcdtNa. $\mathrm{H}_{2} \mathrm{O}(\mathrm{a}, \mathrm{b})$ in their proton NMR spectra exhibit the resonance signals: two overlapping triplets due to 2,6 and $3,5-\mathrm{CH}_{2}$ protons of the heterocyclic rings of 1-MPipz at $\delta 3.70-3.74 \mathrm{ppm}$ and 1-EtPipz at $\delta 2.46 \mathrm{ppm}$ of the corresponding carbodithioate ligands, (Table2). Methyl of $\mathrm{H}_{3} \mathrm{C}-\mathrm{N}<$ group of 4-MPipzcdtNa. $\mathrm{H}_{2} \mathrm{O}$ has been observed to exhibit a singlet at $\delta 2.93 \mathrm{ppm}$. The protons of $-\mathrm{CH}_{3}$ and $-\mathrm{CH}_{2}$ moieties of $\mathrm{H}_{3} \mathrm{C}-\mathrm{CH}_{2}-\mathrm{N}<$ group in 4-EtPipzcdtNa. $\mathrm{H}_{2} \mathrm{O}$ have appeared as a triplet at $\delta$ $0.97-1.01 \mathrm{ppm}$ and as a quartet at $\delta 2.35-2.40 \mathrm{ppm}$ respectively. Another broad band at $\delta 4.28 \mathrm{ppm}$ and $\delta 4.25$ ppm has also been observed in both the carbodithioate ligands. This has been attributed due to the lattice water.<smiles></smiles>

(4-MPipzcdtNa. $\mathrm{H}_{2} \mathrm{O}$ )

(a)<smiles></smiles>

(4-EtPipzcdtNa. $\left.\mathrm{H}_{2} \mathrm{O}\right)$

(b)

In the ${ }^{1} \mathrm{H}$ NMR spectra of the complexes, [Co(NO)(4-RPipzcdt) $)_{2}$ (Figure.2) separate triplets due to 2,6 methylene at $(\delta 3.73-4.00 \mathrm{ppm}$ when $\mathrm{R}=\mathrm{M} ; \delta 2.49-2.72 \mathrm{ppm}$ when $\mathrm{R}=\mathrm{Et})$ and 3,5 methylene at $(\delta 3.05-3.20 \mathrm{ppm}$ when $\mathrm{R}=\mathrm{M} ; \delta 1.81-1.96 \mathrm{ppm}$ when $\mathrm{R}=\mathrm{Et}$ ) have been observed on the downfield and upfield sides respectively in comparison to the free ligands (Table-2). Resolution of the two above said signals in the ${ }^{1} \mathrm{H}$ NMR spectra of the complexes under study in comparison to the free ligands may result because of the hindered rotation of the $\mathrm{S}_{2} \mathrm{C}=-\mathrm{N}$ group of the 4-MPipzcdt and 4-EtPipzcdt ligands. ${ }^{19}$ Upon coordination as the partial positive charge on the nitrogen increases and hence the $\mathrm{C}=-\mathrm{N}$ vibrational frequencies, [Co(NO)(4-EtPipzcdt) $\left.)_{2}\right]\left(1495 \mathrm{~cm}^{-1}\right)>$ [Co(NO)(4-MPipzcdt $\left.)_{2}\right]\left(1491 \mathrm{~cm}^{-1}\right)$, the deshielding of the $\mathrm{N}$-bonded methylene protons in the complexes under study also increases, ${ }^{16,20}$ indicating coordination of the 4-RPipzcdt ligand to the metal ion has been found to cause a deshielding of 2,6 methylene protons and a downfield shift has been observed, while the upfield shift of 3,5 methylene protons inferred increase in electron density because of drainage of the charge from the electron releasing nature of the methyl group of $\mathrm{H}_{3} \mathrm{C}-\mathrm{N}<$ in $\left[\mathrm{Co}(\mathrm{NO})(4-\mathrm{MPipzcdt})_{2}\right]$ and ethyl group of $\mathrm{H}_{3} \mathrm{C}-\mathrm{CH}_{2}-\mathrm{N}<$ in $\left[\mathrm{Co}(\mathrm{NO})(4-\mathrm{EtPipzcdt})_{2}\right]$.

Table 2. ${ }^{1} \mathrm{H}$ NMR spectral data, $\delta(\mathrm{ppm})$ for sodium 4-methylpiperazine-1-carbodithioate monohydrate, sodium 4-ethylpiperazine-1-carbodithioate monohydrate and their cobalt nitrosyl complexes.

\begin{tabular}{|c|c|c|c|c|}
\hline $\begin{array}{l}\text { Sr. } \\
\text { No. }\end{array}$ & Compound & $(3,5-) \mathrm{CH}_{2}(2,6-) \mathrm{CH}_{2}$ & $\mathrm{CH}_{2}\left(\mathrm{C}_{2} \mathrm{H}_{5}\right)$ & $\begin{array}{l}\mathrm{CH}_{3} \& \\
\mathrm{CH}_{3}\left(\mathrm{C}_{2} \mathrm{H}_{5}\right)\end{array}$ \\
\hline \multirow[t]{5}{*}{1.} & 4-MPipzcdtNa. & $3.70-3.74\left(\mathrm{t}, 8 \mathrm{H}: 2,3,5,6-\mathrm{H}_{2}\right)$ & - & \\
\hline & $\mathrm{H}_{2} \mathrm{O}$ & \multirow{2}{*}{$2.46\left(\mathrm{t}, 8 \mathrm{H}: 2,3,5,6-\mathrm{CH}_{2}\right)$} & & $2.93(\mathrm{~s}, 3 \mathrm{H})$ \\
\hline & $\mathrm{H}_{2} \mathrm{O}$ & & $2.35-2.4(\mathrm{q}, 2 \mathrm{H})$ & $0.97-1.01(\mathrm{t}, 3 \mathrm{H})$ \\
\hline & $\begin{array}{l}{[\mathrm{Co}(\mathrm{NO})(4-} \\
\left.\text { MPipzcdt })_{2}\right]\end{array}$ & $\begin{array}{rr}3.05-3.20(\mathrm{t}, 4 \mathrm{H}) \quad \begin{array}{r}3.73-4.00 \\
(\mathrm{t}, 4 \mathrm{H})\end{array}\end{array}$ & - & $3.0-3.05(\mathrm{~s}, 3 \mathrm{H})$ \\
\hline & $\begin{array}{l}{[\mathrm{Co}(\mathrm{NO})(4-} \\
\left.\text { EtPipzcdt })_{2}\right]\end{array}$ & $\begin{array}{rr}1.81-1.96(t, 4 \mathrm{H}) & 2.49-2.72 \\
(\mathrm{t}, 4 \mathrm{H})\end{array}$ & $2.36-2.4(\mathrm{q}, 2 \mathrm{H})$ & $0.98-1.09(\mathrm{t}, 3 \mathrm{H})$ \\
\hline
\end{tabular}

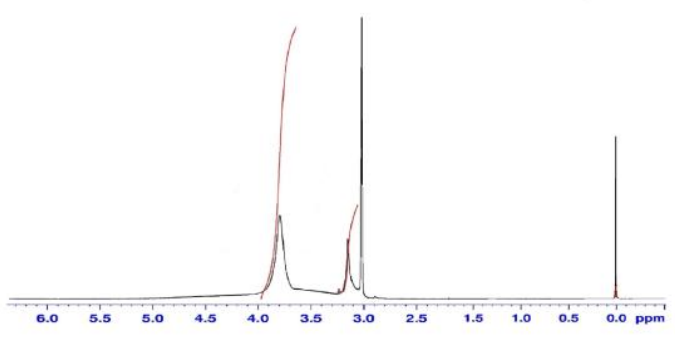

Figure $2:{ }^{1} \mathrm{H}$ NMR spectrum of [Co(NO)(4-MPipzcdt) $\left.)_{2}\right]$ 
${ }^{13}$ C NMR Spectra:

${ }^{13} \mathrm{C}$ NMR spectrum of the complex (Figure 3) exhibits a sharp signal at $\delta 193.07 \mathrm{ppm}$ due to $>\mathrm{NCS}_{2}$, i.e. thiocarboxylato carbon, indicating coordination of sulphur atoms to the cobalt metal ion. This range of ${ }^{13} \mathrm{C}$ signal for $>\mathrm{NCS}_{2}$ group for its binding to the metal ion has also been reported by Rehman et al. ${ }^{21}{ }^{13} \mathrm{C}$ NMR signals due to 2,6-methylene $\left(-\mathrm{CH}_{2}\right)$ carbon atoms at $\delta 40.37-40.53 \mathrm{ppm}, 3,5$-methylene $\left(-\mathrm{CH}_{2}\right)$ carbon atoms at $\delta$ 40.04-40.21 ppm and $\mathrm{CH}_{3}$ carbon at $\delta 39.71-39.87 \mathrm{ppm}$ have also been observed to lie in the range for the respective carbon atoms of the heterocyclic ring. ${ }^{16,22}$ (Table-3).

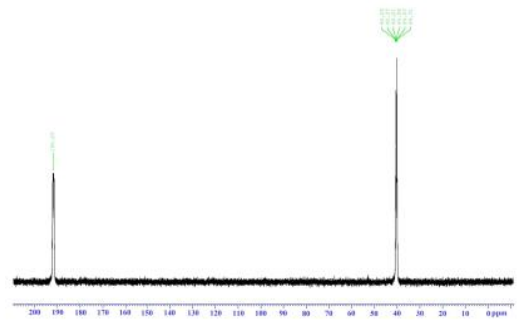

Figure 3: ${ }^{13} \mathrm{C}$ NMR spectrum of [Co(NO)(4-MPipzcdt) $\left.)_{2}\right]$

\section{${ }^{15}$ N NMR Spectra:}

Generally, ${ }^{15} \mathrm{~N}$ chemical shifts in $\mathrm{NO}^{-}$species are significantly more deshielded than those in $\mathrm{NO}^{+}$ systems, $\delta_{\mathrm{N}}$ for $\mathrm{NO}^{-}$in $\mathrm{M}-\mathrm{N}-\mathrm{O}$ systems ranging from about 950 to $350 \mathrm{ppm}$ and for $\mathrm{NO}^{+}$systems from about 200 to $-110 \mathrm{ppm}^{8}$.

In the present complex, i.e. $\mathrm{Co}(\mathrm{NO})(4-\mathrm{MPipzcdt})_{2}$ we have observed a band (Figure 4) at $\delta 202.57$ ppm corresponding to ${ }^{15} \mathrm{~N}$ NMR of $\mathrm{NO}^{+}$group (Table-3). Nitrogen atoms of the heterocyclic rings of 4MPipzcdt ligand i.e. (>S-C-N) have appeared at $106.25 \mathrm{ppm}$ while $\mathrm{CH}_{3}-\mathrm{N}<$ at $53.11 \mathrm{ppm}$ which were in accordance with the range reported for the $\mathrm{N}$ atoms by Joan Mason et al. ${ }^{23}$

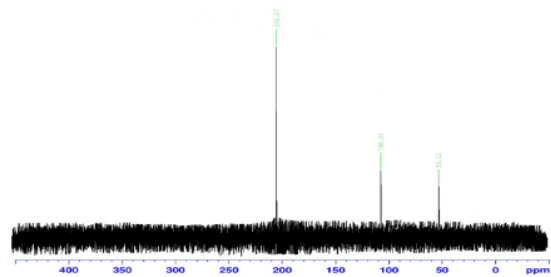

Figure $4:{ }^{15} \mathrm{~N}$ NMR spectrum of [Co(NO)(4-MPipzedt $\left.)_{2}\right]$

Table 3. ${ }^{13} \mathrm{C}$ and ${ }^{15} \mathrm{~N}$ NMR spectral data, $\delta(\mathrm{ppm})$ for Bis(4-methylpiperazine-1-carbodithioato) nitrosonium cobalt(I).

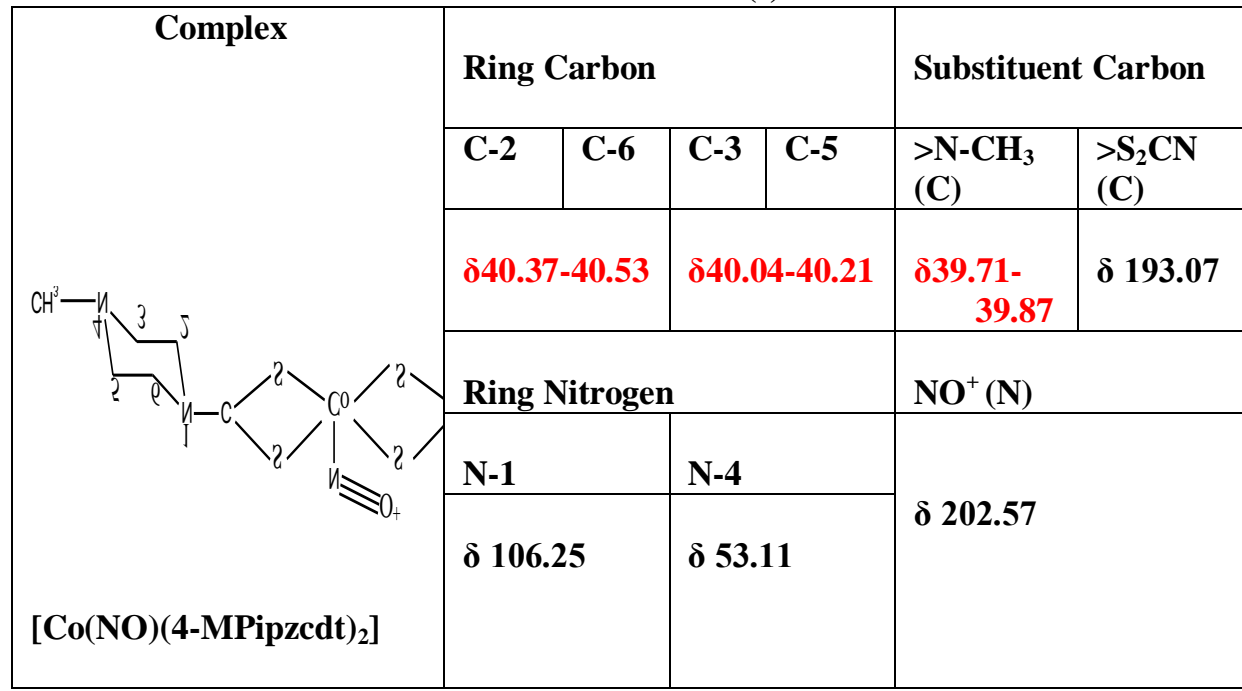


Magnetic Study:

Room temperature and magnetic field dependent magnetic susceptibility measurements of the cobalt nitrosyl carbodithioate complexes, exhibit magnetic moment values in the range 0.02 B.M -0.08 B.M. The $\mu_{\text {eff }}$ values lying near to zero and their non-variation with the increasing/decreasing strength of the magnetic field reveal diamagnetic nature of the complexes. The magnetic study further predicts that metal, i.e. cobalt is in +1 oxidation state, which correspond to a $\mathrm{d}^{8}$ system. The diamagnetism arises because of the pairing of electron spins in the low lying molecular orbitals of the complex with electronic configuration $\left(\mathrm{d}_{\mathrm{xy}}\right)^{2},\left(\mathrm{~d}_{\mathrm{z}}{ }^{2}\right)^{2},\left(\mathrm{~d}_{\mathrm{yz}}\right)^{2} \&$ $\left(\mathrm{d}_{\mathrm{xz}}\right)^{2}$ in a low-spin distorted square pyramidal geometry. ${ }^{24}$

\section{Electronic Spectra:}

The electronic absorption spectra of the complexes, with bent $\{\mathrm{M}(\mathrm{NO})\}^{8}$ and different basal carbodithioate ligands has been explained using the orbital ordering due to Paul A.Duffin et al. ${ }^{24}$ and Joan Mason et al. ${ }^{23}$ Thus, the low spin (singlet state) will have the electronic configuration $\left(\mathrm{d}_{\mathrm{xy}}\right)^{2},\left(\mathrm{~d}_{\mathrm{z}}{ }^{2}\right)^{2},\left(\mathrm{~d}_{\mathrm{yz}}\right)^{2},\left(\mathrm{~d}_{\mathrm{xz}}\right)^{2}$. This configuration would leave the $\pi^{*}(\mathrm{NO})$ group orbitals unoccupied. Ethanolic solution electronic absorption spectra of the complexes exhibit four bands which fall in the regions (I) $11,813-11,715 \mathrm{~cm}^{-1}$, (II) $13,741-13,685$ $\mathrm{cm}^{-1}$, (III) $15,420-15,330 \mathrm{~cm}^{-1}$ and (IV) $20,422-20,361 \mathrm{~cm}^{-1}$. These have been assigned to the transitions, i.e. $\mathrm{d}_{\mathrm{xz}} \rightarrow \pi^{*} \mathrm{NO}, \mathrm{d}_{\mathrm{yz}} \rightarrow \pi^{*} \mathrm{NO}, \mathrm{d}_{\mathrm{z}}{ }^{2} \rightarrow \pi^{*} \mathrm{NO}$ and $\mathrm{d}_{\mathrm{xy}} \rightarrow \pi^{*} \mathrm{NO}$ respectively. A d-d band corresponding to the transition $\mathrm{d}_{\mathrm{xy}} \rightarrow \mathrm{d}_{\mathrm{x}-\mathrm{y}}^{2}$ has also been observed in the range $30,687-30,634 \mathrm{~cm}^{-1}$. These electronic spectral band assignments reveal that the low spin cobalt(I) $\mathrm{d}^{8}$ complexes with $\{\mathrm{Co}(\mathrm{NO})\}^{8}$ under study, have square pyramidal geometry.

\section{Biological Studies:}

Antimicrobial studies of free ligand, 4-MPipzcdtNa. $\mathrm{H}_{2} \mathrm{O}$ and its complex, [Co(NO)(4-MPipzcdt) $\left.{ }_{2}\right]$ against the pathogenic bacteria, Escherichia coli, Salmonella typhi, Enterobacter, Psuedomonas aeruginosa, Shigella flexneri, S.Epidermidis and Salmonella typhimurium using the agar dilution method gave MIC (minimum inhibitory concentration) values in the range $125-500 \mu \mathrm{g} / \mathrm{mL}$ and $31.25-125 \mu \mathrm{g} / \mathrm{mL}$ respectively (Table-4) and reveal them to be moderate antibacterial agents. A decrease in the MIC value upon complexation or the high activity of the cobalt complexes surmounting that of free ligands showed that complexation of the organic ligand and nitrosonium ion to cobalt ion substantially enhances the activity against the pathogenic microbial strains.

Table 4. Antimicrobial activity of some of the compounds.

\begin{tabular}{|c|c|c|c|c|c|c|c|}
\hline \multicolumn{8}{|c|}{ Minimum Inhibitory Concentration $(\mu \mathrm{g} / \mathrm{mL})$} \\
\hline Compound & $\begin{array}{l}\text { Escheric } \\
\text { hia coli }\end{array}$ & $\begin{array}{l}\text { Salmon } \\
\text { ella } \\
\text { typhi }\end{array}$ & $\begin{array}{l}\text { Enter } \\
\text { obact } \\
\text { er }\end{array}$ & $\begin{array}{l}\text { Staphylo } \\
\text { coccus } \\
\text { epidermi } \\
\text { dis }\end{array}$ & $\begin{array}{l}\text { Psuedomo } \\
\text { nas } \\
\text { aeruginos } \\
\text { a }\end{array}$ & $\begin{array}{l}\text { Shigel } \\
\text { la } \\
\text { flexne } \\
\text { ri }\end{array}$ & $\begin{array}{l}\text { Salmonel } \\
\text { la } \\
\text { typhimur } \\
\text { ium }\end{array}$ \\
\hline $\begin{array}{l}\text { 4-MPipzcdtNa } \\
. \mathrm{H}_{2} \mathrm{O}\end{array}$ & 500.00 & 125.00 & 250.0 & 500.00 & 250.00 & 500.0 & 125.00 \\
\hline $\begin{array}{l}{[\mathrm{Co}(\mathrm{NO})(4-} \\
\left.\text { MPipzcdt })_{2}\right]\end{array}$ & 62.50 & 31.25 & 31.25 & 125.00 & 31.25 & 62.50 & 62.50 \\
\hline DMSO & - & - & - & - & - & - & - \\
\hline Penicillin & - & - & - & - & - & - & - \\
\hline
\end{tabular}

\section{References:}

[1.] D.A.Chowdhury; M.N.Uddin; A.K.M.L.Rahman, "Synthesis and Characterization of Dioxo-molybdenum(VI) complexes of some dithiocarbamates". Chiang Mai J. Sci. 33 (3), 357-362, 2006.

[2.] G.Hogarth; K.T.Holman; A.Pateman; A.Sella; J. W.Steed ; I. Richards, "Multiple nitrene insertions into metal-sulfur bonds of dithiocarbamate complexes: synthesis of sulfido-amido and zwitterionic tetraamido complexes". Dalton Trans. 26882695. 2005.

[3.] G. Hogarth, Prog. Inorg. Chem. 53, 7, 2005.

[4.] K.S.Siddiqi; S. A. A. Nami; Lutfullah; Y. Chebude, "Template synthesis of symmetrical transition metal dithiocarbamates". J. Braz. Chem. Soc. 17,1, 2006.

[5.] T.A.Coffey; G.D.Foster; G. Hogarth, J. Chem. Soc., Dalton Trans. 183, 1996.

[6.] P.C.Ford; J. Bourassa; K.Miranda; B.Lee; I.Lorkovic; S.Boggs; S.Kudo; L.Laverman, “ Photochemistry of metal nitrosyl complexes. Delivery of nitric oxide to biological targets". Coord. Chem. Rev. 171, 1, 185-202, 1998

[7.] M.P.Doyle; R.A.Pickering; R.L.Dykstra; B.R.Cook, "Mechanism of nitrosyl transfer. Dissociation of nitric oxide from cobalt nitrosyl”. J. Am. Chem. Soc. 104, 3392-3397, 1982. 
[8.] J.A.McCleverty, "Chemistry of nitric oxide relevant to biology". Chem. Rev. 104, 403-418, 2004

[9.] E.Culotta; Jr. D.E. Koshland, "NO news is good news. (nitric oxide; includes information about other significant advances \& discoveries of 1992) (Molecule of the Year)". Science. 258 (5090), 1862-1864, 1992.

[10.] B.S. Manhas; S.B.Kalia, "Anamalous magnetic behaviour of nitrosyl bis(carbodithioato) iron (I) compounds" Polyhedron . 15 (17), 2949-2952, 1996.

[11.] W.Henderson; J.S. McINDOE, "Mass spectroscopy of inorganic and organometallic compounds". Inorg. Chem. -A wiley textbook series $\mathbf{2 0 0 5}$.

[12.] S.P.Sovilj; K.Babic-Samardzija; N.Avramovie, "Mechanism of mass spectral fragmentation of dinuclear copper(II) complexes with heterocyclic dithiocarbamates and octaazamacrocyclic ligand". Journal of Applied spectroscopy. 72 (1) 37-42, 2005.

[13.] R. Eisenberg, Prog. Inorg. Chem. 12, 295, 1970.

[14.] F. Bonati and Ugo, R. J. Organomets. Chem. 10, 257, 1967.

[15.] J. O.Hill; R. J. Magee, Rev. Inorg. Chem. 3, 141, 1981.

[16.] S.P Sovilj; G.Vuckovic; K.Babic; T. J.Sabo; S.Macura; N. Juranic,“ Mixed-ligand complexes of cobalt(III) with dithiocarbamates and a cyclic tetradentate secondary amine" J. Coord. Chem. 41, 19-25, 1997.

[17.] G.A.Brewer; R.J.Butcher; B.Letafat; E.Sinn, "Spectral analysis of Bis(N,N-diisopropyldithiocarbamato)nitrosyliron, $\mathrm{Fe}(\mathrm{NO})\left[\mathrm{S}_{2} \mathrm{CN}\left(\mathrm{CH}\left(\mathrm{CH}_{3}\right)_{2}\right)_{2}\right]_{2}$, and preparation and crystal structure of its cobalt analogue". Inorg. Chem. 22 (3), $371-375,1983$.

[18.] P.R.H.Alderman; P.G.Owston; J.M.Rowe, "The crystal structure of Nitroso(dimethyldithiocarbonato)cobalt". J. Chem. Soc. 668673, 1962.

[19.] B.F.G. Johnson and K.H. Al-Abaidi, Chem. Commun. 876, 1968

[20.] G. St. Nikolov, Inorg. Nucl. Chem. Lett. 7, 1213, 1971.

[21.] Z.U.Rehman; S.Shahzadi; S.Ali; G.X.Jin, "Preparation, Spectroscopy, Antimicrobial assay, and X-ray structure of Dimethyl bis-(4-methylpiperidine dithiocarbamato-S,S')-tin (IV)". Turk. J. Chem. 31, 435-442, 2007.

[22.] G.N.Kaludjerovic; V.M.Djinovic; S.R.Trifunovic; I.M.Hodzic; T.J. Sabo, "Synthesis and Characterization of tris[butyl-(1-methyl3-phenyl-propyl)-dithiocarbamato]-cobalt(III) seskvitoluene”. J. Serb. Chem. Soc.67 (2), 123-126, 2002.

[23.] J.Mason; L.F.Larkworthy,; E.A.Moore, "Use of Nitrogen NMR Spectroscopy in Metal Nitrosyl Chemistry". Chem. Rev. 102, 913-934, 2002,

[24.] P.A.Duffin,; L.F.Larkworthy,; J.Mason,; A.N.Stephans,; R.M.Thompson, "Ligand Field effects in the Nuclear Magnetic Shielding of Nitrigen-15 and Cobalt-59 in Bent Nitrosyl Complexes of Cobalt(III)". Inorg. Chem. 26, (13), 2034-2040, 1987.

\section{Scheme Caption:}

Scheme 1: Showing fragmentation pattern of $\left[\mathrm{Co}(\mathrm{NO})(4-\mathrm{Mpipzcdt})_{2}\right]$

Figure Captions:

Figure 1 : Mass spectrum of [Co(NO)(4-MPipzcdt) $)_{2}$.

Figure $2:{ }^{1} \mathrm{H}$ NMR spectrum of $\left[\mathrm{Co}(\mathrm{NO})(4-\mathrm{MPipzcdt})_{2}\right]$.

Figure $3:{ }^{13} \mathrm{C}$ NMR spectrum of $\left[\mathrm{Co}(\mathrm{NO})(4-\mathrm{MPipzcdt})_{2}\right]$.

Figure $4:{ }^{15} \mathrm{~N}$ NMR spectrum of $\left[\mathrm{Co}(\mathrm{NO})\left(4-\mathrm{MPipzcdt}_{2}\right]\right.$. 